\section{What is (and what is not) a COPD exacerbation: thoughts from the new GOLD guidelines}

\section{J R Hurst, J A Wedzicha}

\section{Definition of what is (and what is not) a COPD exacerbation}

D uring November 2006 an updated version of the World Health Organisation/US National Heart Lung and Blood Institute global initiative for chronic obstructive lung disease (GOLD) guideline was made available online. ${ }^{1}$ We applaud those involved in creating a living document which has done much to raise the profile of this devastating disease. For many years chronic obstructive pulmonary disease (COPD) was a neglected condition, but research output is now considerable and there have been many developments in the 5 years since the first GOLD report of $2001 .^{2}$ It is widely appreciated that these include an increased understanding of the pathobiology of COPD and the availability of new agents in our evidence-based therapeutic armamentarium. So what else is new in the 2006 GOLD update?

First, and perhaps most importantly, the definition of COPD and the staging classification have been revised. COPD is now defined as a "preventable and treatable disease with some significant extrapulmonary effects that may contribute to the severity in individual patients. Its pulmonary component is characterised by airflow limitation that is not fully reversible. The airflow limitation is usually progressive and associated with an abnormal inflammatory response of the lung to noxious particles or gases". ${ }^{1}$ Although somewhat lengthy, this change of emphasis reflects an admirable attempt to dispel therapeutic nihilism with the recognition that many effective treatments are now available in COPD. Importantly, this also enables us to provide a more positive outlook to our patients. The revised definition now also acknowledges a large and expanding body of work exploring the extrapulmonary manifestations of COPD that include (but are not restricted to) systemic inflammation, ${ }^{3}$ skeletal muscle weakness ${ }^{4}$ and osteoporosis. ${ }^{5}$

With regard to staging, the 2001 document $^{2}$ included a controversial GOLD "stage 0 ", comprising those patients with chronic cough and sputum production but normal spirometry which had been considered "at risk" of progressing to airflow limitation. It is now apparent that this is not necessarily true, and stage 0 has been removed from the 2006 update. The criteria defining stages $1-4$ remain unchanged.

Not only have the definition and staging been updated, but the 2006 revision also includes a definition of COPD exacerbation for the first time. Since the last version of the GOLD guideline there have been a number of advances in the understanding of the pathophysiology of COPD exacerbations, and this is important given the impact of exacerbations on the morbidity, ${ }^{6}$ mortality $^{7}$ and therefore healthcare costs associated with COPD, and the real need for a standardised definition in clinical trials. The GOLD document defines an exacerbation as "an event in the natural course of the disease characterized by a change in the patient's baseline dyspnoea, cough, and/or sputum that is beyond normal day-to-day variations, is acute in onset, and may warrant a change in regular medication in a patient with underlying COPD". ${ }^{1}$ There has been much debate over recent years about how exactly an exacerbation should be defined and two contrasting approaches have been proposed. "Healthcare utilisation" definitions (such as the need, for example, for supplementary oral corticosteroids) are limited by a reliance on factors other than the underlying pathophysiologal process. These include access to health care and the social and financial situation of the patient. Acknowledging that, in practice, exacerbations are often not reported to healthcare professionals for treatment, the new definition states that COPD exacerbations "may warrant a change in regular medication". The alternative to healthcare utilisation definitions are those based solely on patient reported symptom changes. Although these identify a greater number of events, including those in which the patient did not present to a healthcare professional, such definitions can be difficult to validate even in the context of clinical trials. The GOLD definition of an exacerbation therefore represents a pragmatic compromise between these two approaches.

There is, however, a further issue that we suggest has not yet been addressed, either in the GOLD document or by the wider respiratory community. No current definition of exacerbation acknowledges the fact that, in patients with underlying COPD, there are a variety of other pathologies that may cause increased dyspnoea and therefore mimic (or complicate) the exacerbation but which, we suggest, are not causes of it. Such conditions will fulfil the GOLD definition of an exacerbation and include pneumonia, pneumothorax, pulmonary embolus and cardiac failure, among many others. We suggest that such conditions in patients with COPD are primary diagnoses in their own right and are not likely to affect the underlying disease process. Importantly, as described above, COPD is defined in part by the presence of airway inflammation and it is now well established that airway inflammation is enhanced at exacerbation. ${ }^{89}$ This is fundamental since the increased airway inflammation observed in patients susceptible to frequent exacerbation $s^{10}$ may go on to affect disease progression as assessed by the decline in forced expiratory volume in 1 s. ${ }^{11}$ Do such alternative diagnoses upregulate airway inflammation and therefore affect disease progression in COPD? Is it time to rethink our definition of exacerbation to include only those aetiological agents such as microorganisms and pollutants that are associated with increased airway inflammation? Perhaps future definitions of exacerbation, like that of stable disease, should include the caveat "associated with increased airway and systemic inflammation"?

One consequence of defining an exacerbation as associated with increased inflammation is the logical assumption that treatments effective in reducing exacerbation frequency must therefore have antiinflammatory properties. Certainly, there is evidence that inhaled corticosteroids, either alone ${ }^{12}$ or in combination with $\beta_{2}$-agonists, ${ }^{13}$ reduce exacerbation frequency and are, indeed, anti-inflammatory. ${ }^{14}$ However, long-acting anticholinergic drugs are also effective at reducing exacerbation frequency, ${ }^{15}$ yet there is little evidence to suggest that these drugs are anti-inflammatory, and the mechanism of action is more likely to be mediated through their effects on pulmonary mechanics. ${ }^{16}$

There are additional practical difficulties in defining exacerbations as being associated with increased airway inflammation: analysis of sputum or exhaled breath condensate each has problems. Furthermore, we have recently reported a 
large study of systemic biomarkers at exacerbation of COPD suggesting that a suitable plasma biomarker is also currently unavailable. ${ }^{17}$ However, let us not shy away from these difficult concepts and debate what we really mean by "exacerbation of COPD". The inclusion of a definition of exacerbation in the new GOLD guideline is a real step forward and, in the same way that the inclusion of GOLD stage 0 prompted discussion, research and revision to the guideline, we hope that this will now take place in defining exactly what is - and perhaps more importantly what is not-an exacerbation of COPD.

\section{ACKNOWLEDGEMENTS}

We thank Professor Peter Calverley for helpful comments on this manuscript.

Thorax 2007;62:198-199.

doi: $10.1136 /$ thx.2007.077883

\section{Authors' affiliations}

J R Hurst, J A Wedzicha, Academic Unit of Respiratory Medicine, Royal Free \& University College Medical School, London, UK

Correspondence to: Dr J R Hurst, Academic Unit of Respiratory Medicine, Royal Free \& University
College Medical School, Rowland Hill Street, London NW3 2PF, UK; ; irhurst@lineone.net

Competing interests: None declared.

\section{REFERENCES}

1 Anon. 2006 Global strategy for diagnosis, management, and prevention of COPD. www.goldcopd.com (accessed 17 January 2007).

2 Pauwels RA, Buist AS, Calverley PM, et al. Globa strategy for the diagnosis, management and prevention of chronic obstructive pulmonary disease. NHLBI/WHO Global Initiative for Chronic Obstructive Lung Disease (GOLD) Workshop summary. Am J Respir Crit Care Med 2001;163:1256-76.

3 Gan WQ, Man SF, Senthilselvan A, et al. Association between chronic obstructive pulmonary disease and systemic inflammation: a systematic review and a meta-analysis. Thorax 2004:59:574-80.

4 Debigare R, Cote $\mathrm{CH}$, Maltais F. Peripheral muscle wasting in chronic obstructive pulmonary disease. Clinical relevance and mechanisms. Am J Respir Crit Care Med 2001;164:1712-17.

5 Biskobing DM. COPD and osteoporosis. Chest 2002; 121:609-20.

6 Seemungal TAR, Donaldson GC, Paul EA, et al. Effect of exacerbation on quality of life in patients with chronic obstructive pulmonary disease. Am J Respir Crit Care Med 1998;157:1418-22.

7 Soler-Cataluna JJ, Martinez-Garcia MA, Roman Sanchez $P$, et al. Severe acute exacerbations and mortality in patients with chronic obstructive pulmonary disease. Thorax 2005;60:925-31.

8 Hurst JR, Perera WR, Wilkinson TMA, et al. Systemic and upper and lower airway inflammation at exacerbation of chronic obstructive pulmonary disease. Am J Respir Crit Care Med 2006; 173:71-8.

9 Sapey E, Stockley RA. COPD exacerbations. 2 Aetiology, Thorax 2006:61:250-8.

10 Bhowmik A, Seemungal TAR, Sapsford RJ, et al. Relation of sputum inflammatory markers to symptoms and lung function changes in COPD exacerbations. Thorax 2000;55:114-20.

11 Donaldson GC, Wedzicha JA. COPD exacerbations: epidemiology. Thorax 2006;61:164-8.

12 Burge PS, Calverley PM, Jonew PW, et al. Randomised, double blind, placebo controlled study of fluticasone propionate in patients with moderate to severe chronic obstructive pulmonary disease: the ISOLDE trial. BMJ 2000;320:1297-303

13 Calverley P, Pauwels R, Vestbo J, et al. Combined salmeterol and fluticasone in the treatment of chronic obstructive pulmonary disease: a randomised controlled trial. Lancet 2003;369:449-56

14 Hattotuwa KL, Gizycki MJ, Ansari TW, et al. The effects of inhaled fluticasone on airway inflammation in chronic obstructive pulmonary disease: a double-blind, placebo-controlled biopsy study. Am J Respir Crit Care Med 2002:165:1592-6.

15 Niewoehner DE, Rice K, Kote C, et al. Prevention of exacerbations of chronic obstructive pulmonary disease with tiotropium, a once-daily inhaled anticholinergic bronchodilator: a randomized trial. Ann Intern Med 2005;143:317-26.

16 O'Donnell DE, Parker CM. COPD exacerbations. 3 : Pathophysiology, Thorax 2006;61:354-61.

17 Hurst JR, Donaldson GC, Perera WR, et al. Use of plasma biomarkers at exacerbation of chronic obstructive pulmonary disease. Am J Respir Crit Care Med 2006;174:867-74.

\section{LUNG ALERT}

Evidence-based recommendations on the investigation of acute pulmonary embolism

$\Delta$ Stein PD, Woodard PK, Weg JG, et al. Diagnostic pathways in acute pulmonary embolism: recommendations of the PIOPED II investigators. Am J Med 2006;1 19:1048-55.

This paper from the PIOPED (Prospective Investigation Of Pulmonary Embolism Diagnosis) II investigators presents updated guidelines on diagnostic algorithms for pulmonary embolism $(\mathrm{PE})$.

In all cases, an objective clinical assessment of the probability of PE is initially recommended. In patients at low or moderate risk of PE this should be followed by a rapid ELISA-based Ddimer assay. A negative D-dimer effectively allows PE to be ruled out in these groups. Where PE cannot be ruled out, and for those in the high-risk group, CT pulmonary angiography (CTPA) should be performed, ideally with venous phase imaging of the lower leg veins (CT venography).

In moderate- and high-risk patients with a positive CTPA, and low-risk patients with a main or lobar PE on CTPA, treatment is recommended. A negative CTPA in low-risk patients rules out PE. In moderate-risk patients with a negative CTPA only, additional venous ultrasound is recommended to rule out PE. The accuracy of the diagnostic tests is specifically reported.

In patients with discordant findings (low-risk with segmental or sub-segmental PE on CTPA or high-risk with negative CTPA) further imaging is recommended. If not previously imaged, the leg veins should be examined using ultrasound, CT venography or magnetic resonance venography. Further pulmonary imaging may be performed by pulmonary scintigraphy or digital subtraction angiography.

Bedside transthoracic echocardiography and leg ultrasonography are recommended as the initial investigations for patients in extremis, with appropriate further imaging as soon as the patient is stabilised. In pregnancy, D-dimer is recommended after clinical assessment, followed by venous ultrasound and pulmonary scintigraphy or CTPA.

These guidelines provide a rational approach to the common and difficult diagnostic challenges encountered in patients with PE.

S Cowman 